\title{
Scientific Explanation of Light through Phenomenon-based Learning on Junior High School Student
}

\author{
$1^{\text {st }}$ Islakhiyah \\ Graduate Student of Natural Science \\ Education \\ State University of Malang \\ Malang, Indonesia \\ islahmail@gmail.com
}

\author{
$2^{\text {nd }}$ Sutopo \\ Faculty of Mathematics and Natural \\ Sciences \\ State University of Malang \\ Malang, Indonesia \\ sutopo.fisika@um.ac.id
}

\author{
$3^{\text {rd }}$ Lia Yuliati \\ Faculty of Mathematics and Natural \\ Sciences \\ State University of Malang \\ Malang, Indonesia \\ lia.yuliati.fmipa@um.ac.id
}

\begin{abstract}
Abstract. This study was intended to explore the improvement of scores that measure students' scientific explanation of light through phenomenon-based learning. Students conduct an investigation and make an explanation about the phenomenon being observed. The study employed mixed methods with an embedded experimental model. The subject consisted of 28 students of eighth graders in junior high school 3 of Malang, Indonesia. Test, interview, and observation collected the data. Pre-test and post-test scores were analyzed with a paired sample t-test, $\mathbf{N}$-gain score, and d-effect size. The data of pre-test and $\mathrm{N}$-gain score were analyzed with product moment Pearson correlation test. The quality of scientific explanation was collected based on the component that consists of claim, evidence, and reasoning. The result showed that the average of students' scientific explanation scores significantly improved from 1,39 in pre-test into 5,68 in post-test with adeffect size of about 3,6 which was categorized as a strong influence and an average $\mathrm{N}$-gain of 0,40 which was categorized as a medium. Students' scientific explanation shifted significantly from invalid category to fully supported category. The benefits of learning for the improvement of scientific explanation have been obtained by the students equally.
\end{abstract}

Keywords- scientific explanation, phenomenon-based learning, light.

\section{INTRODUCTION}

Knowledge in science is built on the observation of phenomena to explain nature[1]. Scientists build knowledge are deeply committed to the data and evidence to develop a claim, make the argument and analyze evidence related to the theory[2] Following the nature of science, one of the goals of science education in junior high school is engaging students to understand and apply knowledge about science, technology, art, culture related to the phenomena and visible events [3]. Students who have learned science are always expectedto seek knowledge, to sort the knowledge based on the scientific truth, and persuasively communicate through discussion forums related to the science issues to be beneficial for society and environment[2]

The lack of factual knowledge cause light become one of the science topics that the students' mastery of concepts is still on the low-level [4-7]. Students rarely use the knowledge to explain nature phenomenon so it is possessed only on the basic level and less meaningful[7]. Elementary Students assume that light is a source, effect, or circumstances, such as brights. Junior high school students think that light left in the mirror during reflection and the lens must be intact when forming an image [4] High school students have difficulties using ray diagrams to determine image position of the object that located in the water [6]. Undergraduate students have difficulties understanding the basic concepts of geometrical optics [7]. Therefore light is a topic that should be mastered by students from the beginning to support their understanding at the next level.

One of the ways to achieve the goal of science education is engaging students to investigate and use the knowledge to develop scientific explanations [2]. The scientific explanation consists of knowledge and a set of data obtained from the investigation, observation, or literature[8,9] Through investigation, students can practice observing the phenomenon, collecting data and preparing scientific explanations based on the result of data interpretation obtained from the investigation [10]. The junior high school students are expected to draw up a scientific explanation either directly or in writing that consists of claim, evidence, and reasoning [11].

Developing a scientific explanation can facilitate students' learning. Students acquire a deep understanding of the content being studied when devising and maintaining the claim[8,12-14]. They can express ideas explicitly when giving evidence to support the claim[15]. Students can communicate more convincingly by engaging in argumentssupported by empirical evidence[9,16]. They understand better the science ideas by restating explanation and asking questions aboutthe less convincing explanation [11].

Students have difficulties formulating the scientific explanation. They do not know the purpose of writing the scientific explanation and consider that it consists of description and conclusion [13]. Students have difficulty linking evidence and theory [8]. They fail to compile 
scientific explanation because of the less understanding about the content. ${ }^{17}$

The phenomenon can be used as a basis for preparing the scientific explanation. Students practice preparing scientific explanations based on evidence by collecting, discussing and interpreting the observed data of phenomena[10,14]. The scientists also used the phenomenon as the basis for generating a new theory. For example, Ibnu Sahl discovered the law of refraction by investigating the phenomenon of how curved mirrors and lenses bend and focus light $[18,19]$.

The phenomenon in natural science is defined as an event that can be observed or information systems relating to the matter, energy, space and time that logical and can be proved through investigation[20]. It can be used as a source of information to build knowledge through direct observation [21]. For example, Thomas Young investigated the direction of light propagation by observing the phenomenon of light directed at a single slit and forwarded to the double slit[1].

Some previous researches have facilitated the students to develop a scientific explanation[8,15,22], Investigation activity can develop students' skills to construct a scientific explanation[15]. Explicit learning can help students to develop their ability to justify claim using appropriate evidence and reasoning [8]. Some of these studies have involved students in the investigation of the phenomenon in developing a scientific explanation.

\section{A. Scientific Explanation}

Scientific explanation consists of explanations and arguments. The explanation is a statement that answers the question "how" and "why" of events, while the argument is an activity undertaken to justify and defend the explanation either in writing or orally $[8,17]$. There are several theories used to develop a scientific explanation, i.e., the coveringlaw models, causal-mechanical models, a unificationist account of explanation, and pragmatic theories of explanation $[17,23]$

Covering-law models are also called the model of deductive-nomological models. The model proposed by Carl Hempel and Oppenheim in 1948. This model states that the explanation consists of two basic elements namely explanandum and explanans. Explanandum is a sentence that describes the phenomenon, while explanans is the class sentence that proposed to tell about phenomena. Explanandum is a result of explanans. Explanans consists of two subclasses. First, the subclass that states specific conditions and the second is the subclass that declares the common law. The scientific explanation is regarded as a meaning process based on the general law that applies to the phenomena. For example, use the law that light propagates on a straight path to explain the formation of shadows [17].

The causal-mechanical model proposed by Salmon in 1971. According to this model, scientific explanations have to explain a natural structure of phenomena and consistent with a causal relationship. The scientific explanation aims to describe the causal interaction and fundamental mechanism. Causal interaction can be divided into the actual causal processes and pseudo-process. A genuine causal process is a physical event occurs and causes another event, while the pseudo-process is not a physical event and does not cause another event. For example, "a billiard ball strikes another ball and makes it moves" is a genuine causal process while the intersection of the shadows of these balls is a pseudoprocess [17].

Unificationist account of explanation is the idea put forward by Friedman in 1974 when discussing the relationship between scientific explanation and scientific understanding. The example of this model is the use of the law of gravity to explain the phenomenon of gravity and motion of objects in space. Friedman has a general view of the scientific understanding and suggests that scientific explanation should integrate various phenomena to become more comprehensive. This idea is clarified by Kitcher in 1981 to become the Unification explanatory theory. Kitcher argues that the explanation in science cannot be studied one by one, but it is a systematic overview of the natural order [17].

Pragmatic theories of explanation put forward by van Fraassen in 1980. The theory argues that the admissibility of an explanation depends on the context, for example, the background knowledge of the audience. Someone who wants to construct an explanation must connect explanans on explanandum based on his or her understanding while the audience can judge and accept or reject explanations based on their prior knowledge. Explanations are prepared not only based on strong logical structure but also a psychological element. For example, better use Snell's law instead of using the Fresnel equation when discussing the phenomenon of refraction with junior high school students [17].

The components of scientific explanation that originally used the term explanandum, explanans, and general law developed into four components consisting of a phenomenon, theory, data, and reasoning that are more familiar to students [17]. The scientific explanation was also developed using a model of Stephen Toulm in argument into four components consisting of the claim, evidence, reasoning, and rebuttal. The claim is the conclusion that can answer the problem. The evidence is support for a claim that can be the data from observations, measurements, or experiments obtained directly or from a database. The reasoning is a reason why the data are used to support the claim. The rebuttal is a full explanation used as opposed to another explanation why is considered incorrect [8,24]. In this study, the scientific explanation component only limited to the claim, evidence, reasoning, and not to the rebuttal. These three components are set out in Table 1 [25].

\begin{tabular}{lll}
\hline Component & \multicolumn{1}{c}{ Description } & \multicolumn{1}{c}{ Challenging the achievement } \\
\hline Claim & Give statement orthe conclusion that can be tested, & Students make statement or conclusion that can be tested, \\
& which answers the question of "how" or "why" & which responded correctly for a question of "how" or \\
& & "why" and consistent with the available evidence
\end{tabular}


Evidence

Describing the scientificdata which support the claim. The data source can be obtained by students from (but not limited to) the investigation, everyday observation, reading the material, numeric data, and output models

Reasoning
Describe how orwhy the data support the claim, can use the ideas/scientific principles
Students describe the scientific data supporting the claim appropriately and adequate/sufficient

describing how or why the evidence can support the claim, can use the ideas/scientific principles appropriately and valid

\section{B. Phenomenon-Based Learning in Science Education}

Phenomenon-based learning uses a phenomenon as the learning resource $[14,20,26]$. Students can develop a causal explanation of the relationship between components in phenomenon [26]. Phenomenon-based learning facilitates students to learn about natural phenomena through a systematic process using the scientific method. The obtained data are interpreted to produce explanationsthat can develop into tested principles, laws, and theories [27].

Phenomenon-based learning engages students to observe and gather relevant experiences about the phenomenon being studied [14]. Students can use the knowledge that gained from observations to develop and test explanations related to the phenomenon. By arranging the explanation, the students have a better memory than getting it from the teacher [28].

The activities in the phenomenon-based learning are observing the phenomenon, arranging the initial explanation, conducting investigations, drawing up the final explanation, and giving reasons to support the claim. Students observe the phenomenon to study the concept in concrete terms to make it easier to understand the formal concept[29]. After the observations, the students construct an initial explanation as provisional estimates of the answer for the problems that will be investigated. Investigations are carried out to try and observe the phenomenon corresponding to the questions on the worksheet. This activity aimed to gain knowledge and to identify the relationships between the components in the phenomenon as materials to prepare the final explanation. ${ }^{30}$ The final explanation is based on the results of group discussions were carried out after the investigation. Developing scientific explanation can enhance students' understanding of scientific ideas being studied. ${ }^{2}$ Phenomenon-based learning is concluded with a discussion of the scientific explanations that have been prepared. Students present a full explanation and the reasons why the evidence provided to support the claim. The explanation must be supported by the concepts and theories that can be maintained at a discussion forum. ${ }^{2}$ When giving reasons, and students have explicitly expressed his thoughts by connecting theory with the knowledge gained from observations [31,32]. The activities of phenomenon-based learning are presented in Figure 1 [33].

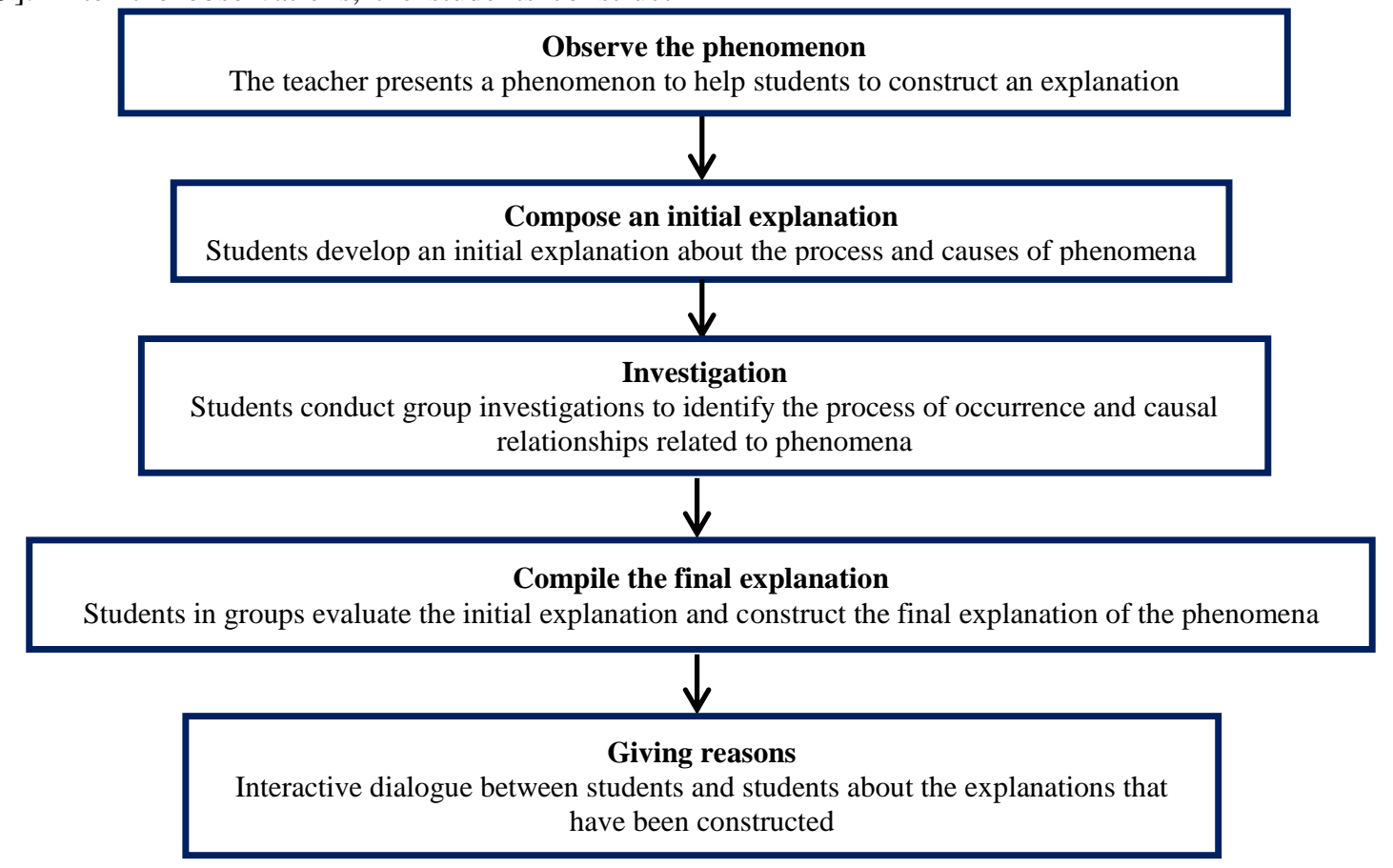

Fig. 1. The Activities of Phenomenon-based Learning 


\section{METHOD}

This study used mixed methods with embedded experimental models[34]. Subjects consisted of 28 students ofeighth graders in junior high school 3 in Malang academic year 2016/2017. The design of the study was using a onegroup pre-test-post-test design to assess the changes in students' scientific explanation score after an intervention [35]. The first step was to conduct preliminary observations and then intervened and proceeded with final observations. Preliminary observations carried out by interviewing the teachers, pre-test, and interviews with students. The intervention implemented by applying phenomenon-based learning on the topic of light for three meetings. Final observations carried out by the post-test and interviews with students. After all the data were collected, then we interpreted the data as a basis to conclude.

The research data consists of quantitative and qualitative data. The quantitative data were obtained from the pre-test and post-test score. The qualitative data were obtained from interviews, student discussion recording, worksheet response, description of pre-test and post-test response, and observation of learning by using videos and photos. A syllabus and lesson plans supported the learning. The syllabus was prepared based on curriculum 2013 and adjusted for research. The Lesson plans were created based

\section{TABLE II. CATEGORIZATION OF RUBRIC FOR SCIENTIFIC EXPLANATION}

\begin{tabular}{|c|c|c|}
\hline Category & Score /level & Description / indicator \\
\hline Fully Supported & 3 & $\begin{array}{l}\text { Two of the following supports the claim about the phenomena } \\
\text { - Evidence from patternsin the data table about the } \\
\text { phenomena being investigated } \\
\text { - Reasoning that connects the data and scientific principles }\end{array}$ \\
\hline Partially Supported & 2 & $\begin{array}{l}\text { One of the following supports the claim about the phenomena } \\
\text { - Evidence from patternsin the data table about the } \\
\text { phenomena being investigated } \\
\text { - Reasoning that connects the data and scientific principles } \\
\text { Or } \\
\text { Incomplete eitherevidence orreasoning support the claim about } \\
\text { the phenomena }\end{array}$ \\
\hline Unsupported & 1 & $\begin{array}{l}\text { The claim leads to the phenomenawithout accompanied by } \\
\text { evidence from patternsinthe data table or scientific reasoning }\end{array}$ \\
\hline Invalid & 0 & No claim indicating to the phenomena \\
\hline
\end{tabular}

The data were analyzed in the form of quantitative and qualitative data. Qualitative data were analyzed based on the quality of scientific explanations constructed by students while answering pre-test and post-testquestions, the description of learning observations, and worksheet response. Shifting the students' responses from pre-test to post-test presented with cross-tabulation. Quantitative data were analyzed based on the scores of scientific explanation in the following order: (1) Presenting the data of pre-test and post-test score using descriptive statistics; (2) Conducting a normality test of pre-test and post-test score by using the Kolmogorov-Smirnov [39], (3) Conducting the difference test of pre-test and post-test score using paired sample $t$-test or Wilcoxon test [38] (4) Calculating individual $\mathrm{N}$-gain score [40], (5) Calculating on the syllabus and equipped with worksheets for investigation. The worksheets consisted of questions that led students to construct explanations based on the observed phenomena.

The research instrument consisted of four essay items. Instruments validated by two lecturers of experts to review the content, language, items conformity with indicators and the construction of a scoring rubric. After validated by the experts, the instruments tested empirically to 32 students of ninth graders. The result of the calculation of the product moment Pearson correlation showed a positive correlation between the score of items and the total score with Pearson coefficient values between 0.375 to 0.882 . The difficulty level for four items indicatedto rigorous criteria with the value between 0.1 to 0.3 [36]. The reliability for four items were being classified on the common criteria with Cronbach's Alpha value of 0.532. To test whether the rubric of scientific explanation was adequate to use, an assessment was done by two correctors. Cohen's Kappa calculation results show that problems Number 1, 2 and 3 belong to the strong criteria and problem Number 4 belongs to the medium criteria being with Kappa values between 0.517 to 0.688 [37]. It can be said that the two correctors mutually consistent in determining a score that scientific explanation rubric is adequate to use [38]. The scientific explanation rubricis presented in Table 2 [25]. 


\section{1) Reflection and Refraction on a Plane Surface}

The reflection process cannot be separated from the process of refraction. When light hits the surface of a substance, some may be reflected, and the other may be refracted simultaneously. Students did preliminary activities by observing the phenomenon. They observed the laser beam directed to the small holes that were arranged in a straight line and winding. Almost all the students concluded that light propagates in a straightline. Then the students observed the laser beam that was directed into the fountain and made the initial explanation that the laser beam was trapped inside the fountain because of the refraction process.

Students investigated groups to practice preparing scientific explanations by answering the following two questions: (1) How large the angle of reflection compared to the angle of incidence when the light hits a plane mirror? Explain. (2) How large theangle of refraction compared to the angle of incidence when the light travels from air to the glass? Explain. To answer the first question, the students observed the phenomenon of a laser beam directed to a plane mirror and then measured the angle of incidence and the angle of reflection. To answer the second question, the students performed more complex activities: (1) Observing the phenomenon of a laser beam directed at the plane-parallel glass. (2) Measuring the angle of incidenceand the angle of refraction. (3) Measuring the distance of the incident ray to the normal line and the distance of the refracted ray to the normal line. (4) Finding the relationship between the distance of the incident ray to the normal line and the distance of refracted ray to the normal line that has a constant value then calculating its average so they can find the value of the refractive index of the glass used in the experiments.

The group of students with absent Number 1, 4, 10, 13, and 20 did not know the concept of the angle of incidence and the angle of reflection. Students assumed that the angle of incidence is the angle formed by the surface of the mirror and the incident ray, and the angle of reflection is the angle formed by the surface of the mirrors and the reflected ray. Teacher improved students' understanding and provide a printout of protractor scale to make students more easily to measure angles. Students can prepare claim adequately and provide evidence in the form of measurement data of the angle of incidence and the angle of reflection but did not give a reason. The example of explanation from students with Absent Number 23 is as follows.

The value of the angle of reflection equal to the angle ofincidence. If the angle of incidence is $30^{\circ}$, the angle of reflection is also $30^{\circ}$ and if the angle of incidence is $60^{\circ}$, the angle of reflectionis also $60^{\circ}$.

Students had difficulties to answer the second question. When determining the relationship between the distance of the incident ray to the normal line and the distance of refracted ray to the normal line, students found two relationships that have a nearly constant value, i.e., the division and subtraction. The teacher led students to decide whether the division or subtraction which is the relation that represents the refractive index of the glass. Students claimed that the division is the proper relationship because it produces a value that has a smaller difference than a subtraction. Students can prepare claim adequately and provide evidence in the form of measurement data (see Fig. 2). Students cannot give a reason why the angle of refraction is always smaller than the angle of incidence when light travels from air into glass although they had discovered the value of the refractive index of the glass of \pm 1.5 and knew the value of the refractive index of air that was listed on the worksheet.

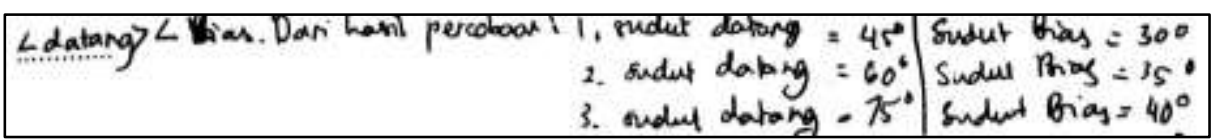

In English:

The angle of incidence > the angle of refraction. From the experiments:

1. the angle of incidence $=45^{\circ}$, the angle of refraction $=30^{\circ}$

2. the angle of incidence $=60^{\circ}$, the angle of refraction $=35^{\circ}$

3. the angle of incidence $=75^{\circ}$, the angle of refraction $=40^{\circ}$

Fig. 2. The example of student'sscientific explanation when light travels from air into glass

The investigation was continued by making a final explanation of the laser beam that trapped inside the fountain. The teacher asked questions about the behavior of light when propagating in the opposite direction, i.e., from the glass into the air, untilthe topic of total internal reflectionprocess so the students can conclude that the laser beam was trapped inside the fountain due to a total internal reflection process.

\section{2) The Concave Mirror and the Convex Mirror}

Students did the preliminary activities by observing the phenomenon via video. Students watched a video of someone who cooked water using the parabolic solar cooker and someone who ripened food using the "Gosun" oven concave-shaped elongated. Students made an initial explanation thatthe rays on a concave mirror will be focused into a single point.

The students carried the exploratory activities by preparing the scientific explanation to answer the question "does the changeof the object distance affect the properties and the distance of image if the object is in 
front of a concave mirror or a convex mirror? Explain". To answer this question, they did the experiments with the following steps: (1) Finding the focus of concave mirrors by measuring the image distance of scenery to the screen. (2) Putting the candle as an object in front of the concave mirror (could be at a greater distance from the focus or more than twice the focus) and identifying image forming. (3) Changing the distance of the candle toward the concave mirror to find the image with different properties. (4) Putting the candle as an object in front of a convex mirror and identifying image forming. (5) Changing the distance of candletoward the convex mirror and see if the image is formed with different properties.

Students were less careful in preparing claims for the question relating to the concave mirror and a convex mirror that require more than one claim. Students only focused on the concave mirror so the claims that were arranged mostly stated that "the changes of the object distance affect the properties and the distance of the image". This claim only applies to the concave mirror and does not apply to the convex mirror. Students are still confused claiming although had observed properties of the image that is always unchanged (virtual, upright, diminished) when objects placed in front of a convex mirror with an arbitrary distance. Some students can provide the appropriate claim, giving evidence by spelling outthe measurement data of image distance, but only gave a tautology reasoning. At the end of the lesson, the students concluded that the concave mirror is collecting rays, sothe collected rays produce enough heat to ripen the food as the phenomenon was presented at the beginning of learning.

\section{3) The Convex Lens and the Concave Lens}

Students investigated groups to practice preparing scientific explanations by answering the question "does the change of the object distance affect the properties and the distance of image if the object is in front of a convex lens or a concave lens? Explain". To answer this question, students did the experiments with the following steps: (1) Finding the focus of a convex lens by measuring the imagedistance of scenery to the screen. (2) Putting the candle as an object in front of the convex lens (may be at the greater distance from the focus, or more than twice the focus) and identifying image forming. (3) Changing the distance of the candle toward the convex lens to find an image with different properties. (4) Putting the candle as an object in front of a concave lens and identifying image forming. (5) Changing the distance of candle toward the concave lens and see if the image is formed with different properties.

Students can arrange the appropriate claim although initially had experienced confusion when answering questions on a worksheet. The dialogue took place between teacher and students when a group had difficulties in finding the image of the concave lens. The phenomenon can be the basis for determining claims (Line 7), so the students can determine the claims appropriately (Line 13).
1. S: "On this question (based on experiments of the convex lens and a concave lens, does the change of object distanceaffect the properties and the distance of the image?) When we said yes, whether the reason is also mentioned, Ma'am?".

2. T: "Of course. Does the change of the object distance affect the properties and the distance of the image? ".

3. S: "We did not find the image formed by a concave lens, Ma'am?".

4. T: "That outside the lens, what if inside the lens?".

5. S: (Looking into the lens) "Yes, there are".

6. Q: "That is the image formed by a concave lens. If not formed outside the lens, it is mean virtual orreal? ".

7. S: "Virtual". (Then the student see the image of a wall decoration through a concave lens) "So the properties are virtual, upright, and diminished. Oh, it means that the concave lens also has an image ..."

8. Q:" Remember, what was the properties, virtual or real? ".

9. S: "Virtual, upright, diminished".

10. Q: "Try to change the object distance, are the properties fixed or changed?".

11. S:(Trying) "Fixed Ma'am. Virtual, upright, diminished ".

12. Q: "So, does the change of the object distance affect the properties of the images?".

13. S: "If the concave lens, no. If the convex lens, yes ".

Investigation activities followed by constructing the final explanation. Students can provide the appropriate claim, giving evidence by spelling out theimage distance measurement data and provide support in the form of ray diagram or comparison of measurement results with calculations via an equation.

\section{B. Description of Data and Discussion}

The scientific explanation in this study was analyzed using a scientific explanation rubric [25]. For scoring, scientific explanations were categorized into levels 0 (invalid), level 1 (unsupported), level 2 (partially supported), and level 3 (fully supported). The statistics descriptive of students' scientific explanations score inpretest and post-test are presented in Table 3. The results of the Kolmogorov-Smirnov normality test suggested that pre-test and post-test score data are not normally distributed with a significance value of 0.000 for pre-test and 0.002 for post-test scores [39]. The Wilcoxon test results show that the pre-test and post-test scores significantly differed with Asymp.sig. values of $0,000 .{ }^{38}$

TABLE III. Statistics-DESCRIPTIVE OF StUdents' SCIENTIFIC EXPLANATIONS SCORE

\begin{tabular}{lccc}
\hline & Pre-test & Post-test & $\boldsymbol{N}$-gain score \\
\hline Number of Data (N) & 28 & 28 & 28 \\
Average & 1,39 & 5,68 & 0,402 \\
Standard Deviation & 1,133 & 1,219 & 0,111 \\
Skewness & 0,779 & $-0,515$ & $-0,996$ \\
\hline
\end{tabular}

Based on the Wilcoxon test results and the average score of pre-test and post-test score in Table 3, it can be concluded that there was a significant improvement in the score of scientific explanation after the lesson implemented. How large the improvement can be seen 
from the average of individual $N$-gain score of 0.402 which was included in the medium category. ${ }^{40}$ The frequency distribution of students' $N$-gain score is presented in Table 4.

TABLE IV. FREQUENCY DisTRIBUTION OF STUDENTS'N-GAIN SCORE

\begin{tabular}{llcc}
\hline $\boldsymbol{N}$-gain score & Category & Frequency & Percentage (\%) \\
\hline$(<\mathrm{g}>) \geq 0,7$ & High & 0 & 0 \\
$0,7>(<\mathrm{g}>) \geq 0,3$ & Medium & 26 & 83 \\
$(<\mathrm{g}>)<0,3$ & Low & 2 & 7 \\
\hline
\end{tabular}

How strong the influence of learning in improving student scores can be seen from the value of $d$-effect size. The result of the calculation of $d$-effect size showed that the role of learning belonged to the high category with the $d$-effect size of 3.6 [38]. It can be concluded that phenomena-based learning had a strong influence in improving students' scientific explanation score.

Table 4 shows that all the individual $\mathrm{N}$-gain scores were positive. It was used as the assumptions to determine the usefulness of learning experienced by students. A correlation test was done to determine the relationship between pre-test scores and individual $\mathrm{N}$-gain scores. The result of the Kolmogorov-Smirnov normality test showed that the data of pre-test scores and $\mathrm{N}$-gain scores were not normally distributed, so the Spearman Rank correlation test was conducted. A correlation test result showed that there was no significant correlation between the score of pre-test and $\mathrm{N}$-gain score with significant value $0.413>$ 0.05 . It showed that students who hadlow pre-test scores got the same improvement as students who had high pretest scores. This resultwas confirmed by the calculation of the $\mathrm{N}$-gain average score equal to the average of the individual $N$-gain score $(\mathrm{g}=\overline{\mathrm{g}})$ of 0.40 . It was concluded that the students obtained the benefit of learning equally. ${ }^{41}$ TABLE V. $\quad N$-GAIN SCORE OF EACH ITEM

\begin{tabular}{lcccc}
\hline Number & $\mathbf{1}$ & $\mathbf{2}$ & $\mathbf{3}$ & $\mathbf{4}$ \\
\hline$\sum$ Pre-test score & 18 & 12 & 2 & 7 \\
$\sum$ Post-test score & 31 & 56 & 33 & 39 \\
$N$-gain score & 0,2 & 0,6 & 0,4 & 0,4 \\
\hline
\end{tabular}

The changeof scientific explanation can be seen through the $N$-gain score of each item presented in Table 5. There was the improvement of scientific explanation scores for each item. The most significant improvement occurred in question Number 2. The students' responses to each item were described as follows.

1) Problem Number 1: Reflection on the Plane Mirror

Giventhe figure of a house plan, students were asked to explain how to put two plane mirrors that can be used to see the front door (Point A) from the kitchen (Point B) (see Fig. 3). Percentage of students who were at the bottom two levels decreased from $100 \%$ in pre-test to $89 \%$ in post-test (see Table 6). The percentage of students who were at the top two level increased from $0 \%$ in pretest to $11 \%$ in post-test.

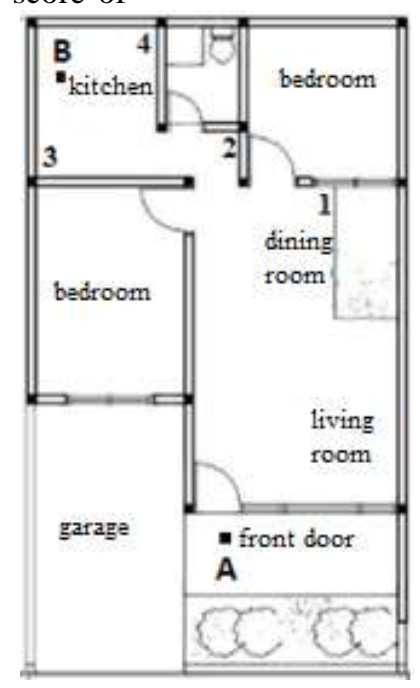

Fig. 3. House Plan in Problem Number 1

TABLE VI. Cross-TABUlation OF STUdENTS’ SCIENTIFIC EXPLANATION SCORE FOR Problem Number 1

\begin{tabular}{|c|c|c|c|c|c|c|c|}
\hline \multicolumn{8}{|c|}{ Pre-test } \\
\hline & Category & Invalid & Unsupported & $\begin{array}{c}\text { Partially } \\
\text { Supported }\end{array}$ & $\begin{array}{c}\text { Fully } \\
\text { Supported }\end{array}$ & Total & $\begin{array}{c}\text { Percentage } \\
(\%)\end{array}$ \\
\hline \multirow[t]{4}{*}{ Post-test } & Invalid & 0 & 0 & 0 & 0 & 0 & 0 \\
\hline & Unsupported & 8 & 17 & 0 & 0 & 25 & 89 \\
\hline & Partially Supported & 2 & 1 & 0 & 0 & 3 & 11 \\
\hline & Fully Supported & 0 & 0 & 0 & 0 & 0 & 0 \\
\hline \multicolumn{2}{|l|}{ Total } & 10 & 18 & 0 & 0 & 28 & 100 \\
\hline \multicolumn{2}{|c|}{ Percentage (\%) } & 36 & 64 & 0 & 0 & 100 & \\
\hline
\end{tabular}




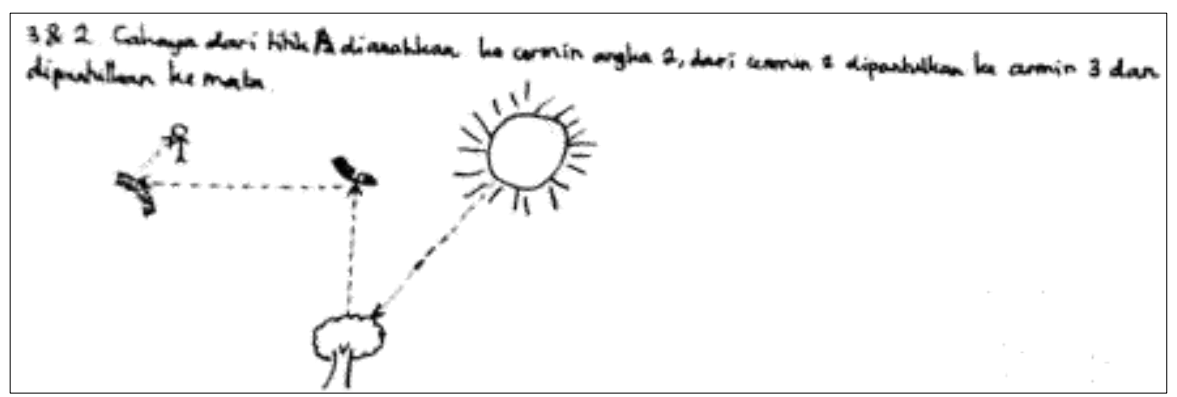

In English:

$3 \& 2$. The light at Point $\mathrm{A}$ is directed to the mirror at Point 2, from the mirror at Point 2 reflected to mirror at Point 3 then to the eye.

Fig. 4. Example of Students'Scientific Explanation in Pre-testfor Problem Number 1

Students who were in the invalid category in pre-test indicated that they did not the know to construct a claim of the reflection on a plane mirror. Most students in the unsupported category gave the right claim but did not give evidence and reasoning to support the claim. Students supported the claim with an analogy of a plane mirror position to the principle of a periscope but did not spell out how is the principle of the periscope. Other students supported the claim by giving the reasoning in the form of light propagation process but did not spell out how the direction toward the mirror so the light can get to the observer (see Fig. 4). Based on the interview, the student got the difficulties in determining the angle and the position of the mirror.

The quality of students' scientific explanation improves from unsupported categories to partially supported in post-test. Interviews showed that students had understood the principle of reflection on a plane mirror, but they still have difficulties in drawing the rays on the mirror at an angle so they cannot find the angle of incidence. Students in the partially supported category give incomplete evidence and reasoning. They described the propagation of light and mentioned the angle of incidence but did not show the propagation of light using the diagram (Fig. 5). Students do not come to fully supported category because they cannot give evidence and appropriate reasoning.

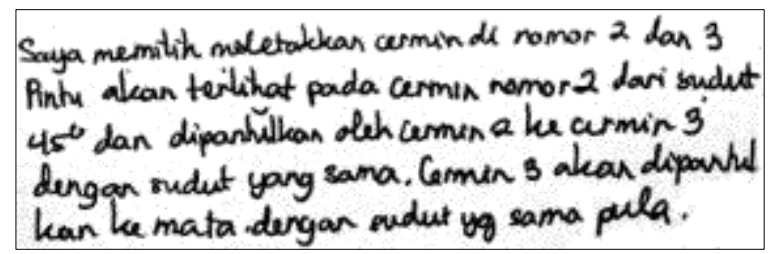

In English:

I chose to place a mirror at points 2 and 3 . The door will be visible in the mirror at point 2 from corner $45^{\circ}$ and reflected by mirror 2 to mirror 3 with the same angle. Mirror 3 will reflect the light to the eye with the same angle

Fig. 5. Example of Students' Scientific Explanation in Post-test for Problem Number 1

2) Problem Number 2: Refraction in Plane Surface

Given the refractive index data table of some substances (Table 7), students were asked to explain correctly whether true or not the two refraction figures of light passing through two different mediums (Fig. 6). The percentage of students who were at the bottom two levels decreased from $96 \%$ in pre-test to $11 \%$ in post-test (see Table 8). The percentage of students who were at the top two levels increased from $4 \%$ in pre-test to $89 \%$ in posttest.

TABLE VII. REFRACTIVE INDEX DATA OF SUBSTANCES

\begin{tabular}{lll}
\hline No. & Substance & The refractive index \\
\hline 1. & air & 1 \\
2. & water & 1,3 \\
3. & ethyl alcohol & 1,4 \\
4. & oil & 1,5 \\
5. & glass & 1,5 \\
\hline
\end{tabular}

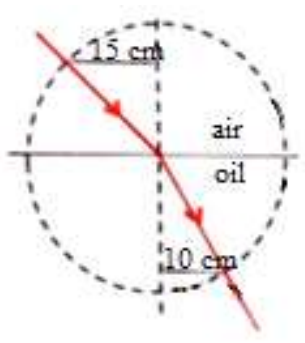

(a)

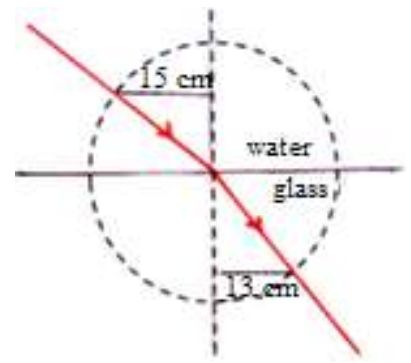

(b)
Fig. 6. Refraction of Light Passing Two Different Mediums

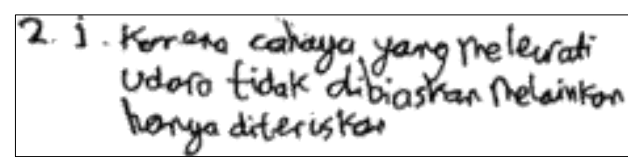

In English:

The figure Number $i$ is correct because the light that was passing through the air is not refracted but only continued

Fig. 7. Example of Students' Scientific Explanation in Pre-test for Problem Number 2

Students in the invalid category in pre-test compiled improper claims and reasons (see Fig. 7). It indicates the students' had not known refraction on a plane surface. Interviews showed that students could not understand the question because they did not know about the concept of the incident ray, the refracted ray, the normal line, and the refractive index 
Table 8 shows the improvement of students in the partially supported category that indicates most students already know the principle of refraction in post-test. Students have understood the relationship between the distance of incident ray and the distance of refracted ray toward the normal line to the refractive index both of the medium so the students can apply it to support the claim. Students in the fully supported category gave reasoning byusing the principle of refraction when the light passes through a different mediums and provided evidence by calculating the ratio of the distance of incident ray and the refracted ray toward the normal line equal to the ratio of refractive index both of the medium to support the claim (see Fig.8).

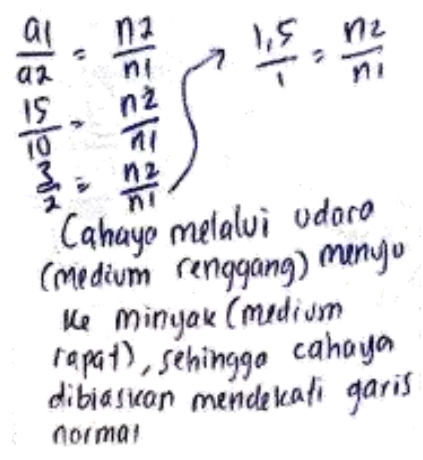

(a)

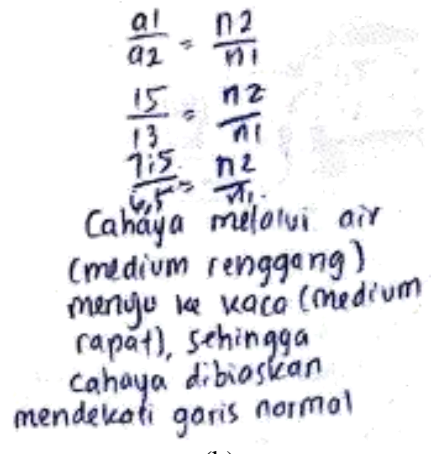

In English:

(b)

Light passes through the water (less dense medium) to the glass (more dense medium), so the refracted ray lies closer to the normal line

Fig. 8. Example of Students' Scientific Explanation in Post-test for Problem Number 2

In English:

Light passes through the air (less dense medium) to the oil (more dense medium), so the refracted ray lies closer to the normal line

TABLE VIII. FREQUENCY DistribUtion OF STUDENTS'N-GAIN SCORE

TABLE 8. Cross-tabulation of Students'Scientific Explanation Score for Problem Number 2

\begin{tabular}{|c|c|c|c|c|c|c|c|}
\hline \multicolumn{6}{|c|}{ Pre-test } & \multirow[b]{2}{*}{ Total } & \multirow[b]{2}{*}{$\begin{array}{c}\text { percentage } \\
(\%)\end{array}$} \\
\hline & Category & Invalid & Unsupported & $\begin{array}{c}\text { Partially } \\
\text { Supported }\end{array}$ & $\begin{array}{c}\text { Fully } \\
\text { Supported }\end{array}$ & & \\
\hline \multirow[t]{4}{*}{ Post-test } & Invalid & 0 & 0 & 0 & 0 & 0 & 0 \\
\hline & Unsupported & 2 & 1 & 0 & 0 & 3 & 11 \\
\hline & Partially Supported & 15 & 6 & 1 & 0 & 22 & 78 \\
\hline & Fully Supported & 0 & 3 & 0 & 0 & 3 & 11 \\
\hline \multirow[t]{2}{*}{ Total } & & 17 & 10 & 1 & 0 & 28 & 100 \\
\hline & Percentage (\%) & 61 & 35 & 4 & 0 & 100 & \\
\hline
\end{tabular}

1) Problem Number 3: Image Formation of Objec tat The Bottom of Pool

Given an image of an object which is at the bottom of the pool (Fig. 9), students were asked to explain where the possibility of the image formed when viewed by the observer from the surface of the pool. The percentage of students who were at the bottom two levels decreased from $100 \%$ in pre-testto $58 \%$ in post-test (see Table 9). The percentage of students at the top two levels increased from $0 \%$ in pre-test to $42 \%$ in post-test.

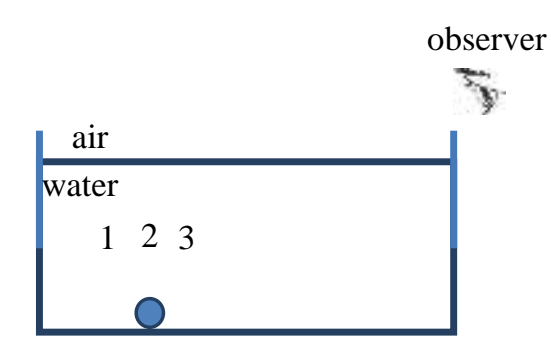

Fig. 9. Figure of Object at the bottom of Pool

Table 9 shows that almost all of the students were in the invalid category in the pre-test. The students made wrong claim to determine the position of the image (see Fig. 10). They had a wrong concept by comparing the refractive index of air with the refractive index of the water to calculate the value of refraction and determining 
the position of the image based on the value of refraction. The students understood that the refraction is the bending of light when passing through a different medium but the students only gave a wrong reason. Students in the unsupported category constructed claim appropriately without providing evidence and reasoning, they only guessed an answer without a rationale.

TABLE 9. Cross-tabulation of Students' Scientific Explanation Score for Problem Number 3

\begin{tabular}{llcccccc}
\hline \multicolumn{2}{c}{ Pre-test } & & & & & \\
& Category & Invalid & Unsupported & $\begin{array}{l}\text { Partially } \\
\text { Supported }\end{array}$ & $\begin{array}{l}\text { Fully } \\
\text { Supported }\end{array}$ & Total & $\begin{array}{c}\text { Percentage } \\
(\%)\end{array}$ \\
\hline Post-test & Invalid & 9 & 0 & 0 & 0 & 9 & 33 \\
& Unsupported & 7 & 0 & 0 & 0 & 7 & 25 \\
& Partially Supported & 9 & 1 & 0 & 0 & 10 & 35 \\
& Fully Supported & 1 & 1 & 0 & 0 & 2 & 7 \\
Total & 26 & 2 & 0 & 0 & 28 & 100 \\
\multicolumn{2}{l}{ Percentage (\%) } & 93 & 7 & 0 & 0 & 100 & \\
\hline
\end{tabular}

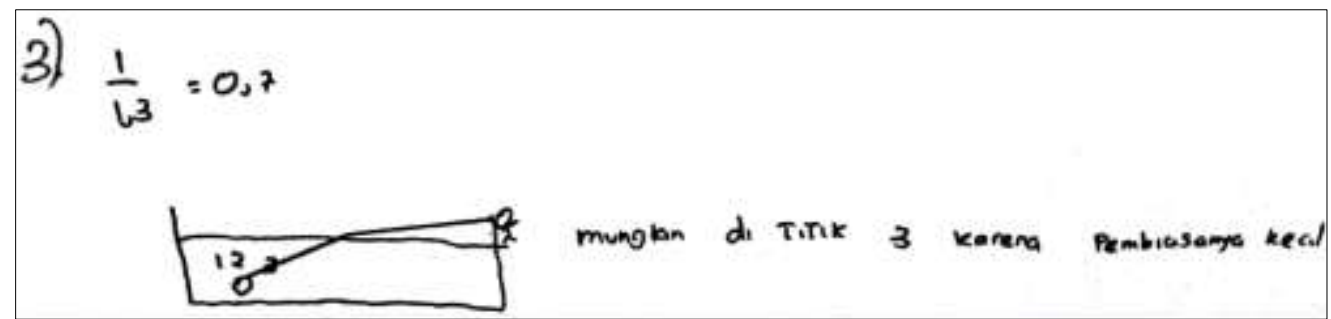

In English:

Probably at point 3 because the refraction is small

Fig. 10. Example of Students' Scientific Explanation in Pre-test for Problem Number 3
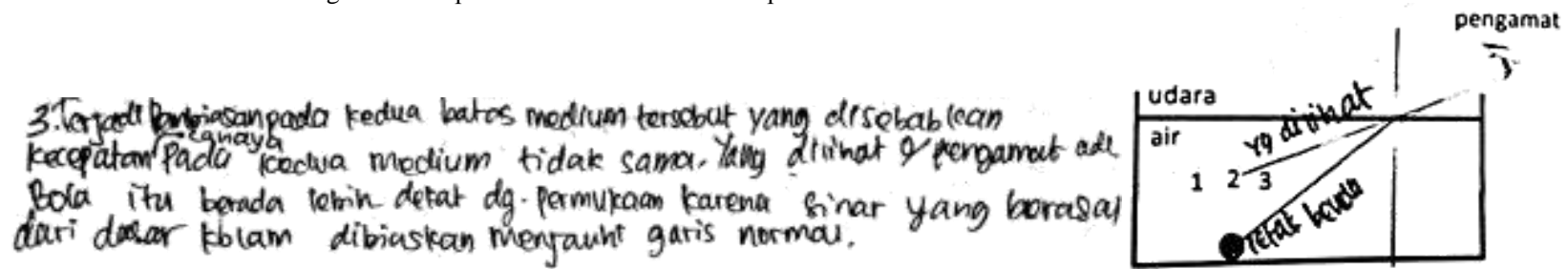

In English:

Refraction occurs at the surface boundary of the two mediums due to the speed of light on the two mediums is not the same. Which the observer sees is that object is closer to the surface because the light coming from the bottom of the pool is refracted away from the normal line.

Fig. 11. Example of Students' Scientific Explanation in Post-test for Problem Number 3

1) Problem Number 4: The Formation of the image on a Concave Mirror

TABLE 10. Cross-tabulation of Students' Scientific Explanation Score for Problem Number 4

\begin{tabular}{|c|c|c|c|c|c|c|c|}
\hline \multicolumn{6}{|c|}{ Pre-test } & \multirow[b]{2}{*}{ Total } & \multirow[b]{2}{*}{$\begin{array}{c}\text { Percentage } \\
(\%)\end{array}$} \\
\hline & Category & Invalid & Unsupported & $\begin{array}{l}\text { Partially } \\
\text { Supported }\end{array}$ & $\begin{array}{l}\text { Fully } \\
\text { Supported }\end{array}$ & & \\
\hline \multirow[t]{4}{*}{ Post-test } & Invalid & 1 & 0 & 0 & 0 & 1 & 4 \\
\hline & Unsupported & 13 & 2 & 0 & 0 & 15 & 53 \\
\hline & Partially Supported & 7 & 5 & 0 & 0 & 12 & 43 \\
\hline & Fully Supported & 0 & 0 & 0 & 0 & 0 & 0 \\
\hline \multicolumn{2}{|l|}{ Total } & 21 & 7 & 0 & 0 & 28 & 100 \\
\hline \multicolumn{2}{|c|}{ Percentage $(\%)$} & 75 & 25 & 0 & 0 & 100 & \\
\hline
\end{tabular}




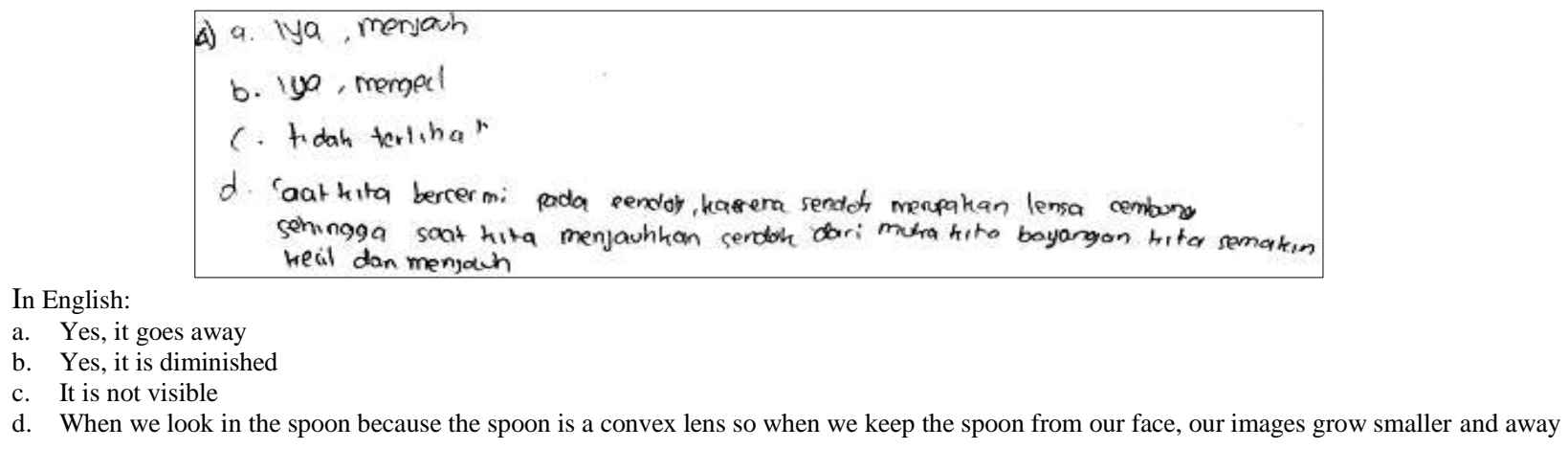

Fig. 12. Example of Students' Scientific Explanation in Pre-test for Problem Number 4

Students were asked to explain how does the image of object changes if the object distance turned away from the concave mirror. The percentage of students who are at the bottom two levels decreased from $100 \%$ in pre-test to $57 \%$ in post-test (see Table 10). The percentage of students at the top two levels increased from $0 \%$ in pretest to $43 \%$ in post-test.

Table 10 shows that most of the students were in the invalid category in the pre-test. It indicates that the students did not know the process of the formation of images. Students made a claim based on the experience gained from everyday life. Students gave a reason by comparing image on a concave mirror with animage on a spoon (see Fig. 12).

Table 10 shows that the percentage of students in the invalid category and unsupported categoryshiftedto the partially supported category in post-test. Based on interviews, the students in the unsupported category still have difficulties in calculating the distance and magnification of the image when the object was at an infinite distance. Other students in the unsupported category have been able to collect the data but can not interpret the data and use the data as evidence for determining the change of image when the object moved away from the concave mirror. Students in the partially supported category calculated and interpreted the data appropriately so they can answer questions and provide support for their claims but their reasoning was still tautologies, so there were no students in the fully supported category (see Fig. 13).

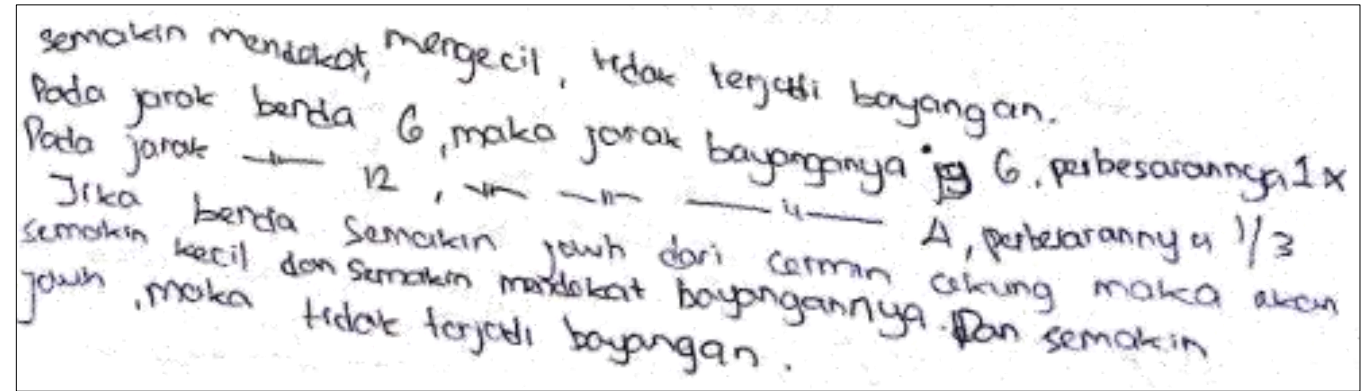

In English:

Getting closer, smaller, no image.

When the object distance is $6 \mathrm{~cm}$, the distance of the image is also $6 \mathrm{~cm}$, the magnification is 1 .

When the object distance is $12 \mathrm{~cm}$, the distance of the image is $4 \mathrm{~cm}$, the magnification is $1 / 3$.

If the object moves far away from the concave mirror, then the image will be smaller and closer. If the farthest away, no image is formed.

Fig. 13. Example of Students' Scientific Explanation in Post-test for Problem Number 4

Before learning, students' scientific explanations were in invalid, unsupported and partially supported categories. Students were in the invalid category because they did not know to make claims related to the given problem. Students in the unsupported category can construct claims appropriately but do not provide support for claims that had been prepared because they did not have knowledge related to the problem and they just guessed the answer. Students in the partially supported category knew to support the claim, but it was incomplete because limited to the experience gained from daily life.
There was an improvement in the quality of students' scientific explanations after the learning was done. Students can make an explanation until the fully supported category when answering the posttest problem. The invalid category declined and moved to a higher category in answering all given problems. This increase occurs because the students practice composing a scientific explanation of the relationship between the angle of incidence and the angle of reflection based on the reflection phenomenon on the plane mirror. Students also practiced constructing an explanation of the relationship between the angle of incidence and the angle of refraction 
based on the refraction phenomenon of the plane-parallel glass and constructing explanation about the influence of the object distance to the properties and the distance of the image if the object is in front of a concave or a convex mirror. Phenomena can motivate students to make explanations [42]. Phenomena also can help students to make claims through observation, search for evidence and provide reasoning through measurement and investigation activities. The investigation of phenomena produces data patterns that can be used as evidence and materials to construct conclusions so cancultivate students' thinking and reasoning. The learning that gives students more opportunity to observe directly can cultivate students' critical thinking skills [43]. Critical thinking skills are needed in building scientific explanations[44].

\section{CONCLUSION}

The scientific explanation improved after phenomenon-based learning on the topic of light. Improvement occurs in all given issues. The quality of students' scientific explanationsincreased toward the higher category. This increase occurred because students practiced composing a scientific explanation of the relationship between the angle of incidence and the angle of reflection of the plane mirror. The relationship between the angle of incidence and the angle of refraction in the plane-parallel glass, and the effect of the object distance to the properties and distance of the image if the object placed in front of a concave mirror or a convex mirror. When developing a scientific explanation, students practiced developing claims based on observed phenomena during the investigation. Students also practiced searching for evidence based on data collected through investigation.

Students' scientific explanation have increased toward the higher category after phenomenon-based learning was implemented. The increase can be seen from the $N$-gain score of 0.40 which was included in the medium category and the $d$-effect size of 3.6 which was included in the high category. The increase was due to the phenomenon of helping students to make claims, seek evidence and provide reasoning through observation and investigation activities. There was no significant relationship between pretest score and the $\mathrm{N}$-gain score of students' scientific explanation so it can be concluded that the benefits of learning in developing scientific explanation obtained by students equally because every student got the same opportunity to practice preparing a scientific explanation and observing the phenomenon during the investigation.

\section{REFERENCES}

1. A. E. Lawson, "The generality of hypotheticodeductive reasoning: Making scientific thinking explicit," The American Biology Teacher vol.62(7), pp 482-495, 2000.

2. NRC, "A Framework for K-12 Science Education: Practices, Crosscutting Concepts, and Core Ideas ,"
Washington, DC: The National Academies Press, 2012.

3. Directorate General of Primary and Secondary Education, Ministry of Education and Culture, "Peraturan Menteri Pendidikan dan Kebudayaan RI No. 24 Tahun 2016 tentang Kompetensi Inti dan Kompetensi Dasar Pelajaran Kurikulum 2013 SD/MI, SMP/MTs., SMA/MA dan SMK/MAK," see http://dikdasmen.kemdikbud.go.id/index.php/permen dikbud-no-24-tahun-2016/.

4. R. Driver, A. Squires, P. Rushworth \& V. W. Robinson, "Making Sense of Secondary ScienceResearch into Children Ideas," London and New York: Routledge, 2006.

5. Rusilawati,"Diagnosis Kesulitan Belajar Fisika Siswa SD, SMP, dan SMA dengan Teknik General Diagnostic dan Analytic Diagnostic," Peningkatan Keprofesionalan Peneliti, Pendidik \& Praktisi MIPA National Conference Proceedings, Yogyakarta: Faculty of Mathematics and Science of Yogyakarta State University, 2007.

6. K. Kaewkhong, A. Mazzolini, N. Emarat, \& K. Arayathanitkul, "Thai high-school students' misconceptions about and models of light refraction through a planar surface," Physics Education vol.45 (1), p 97, 2010

7. Sutopo, "Miskonsepsi Pada Optika Geometri dan Remediasinya.," J-TEQIP. V(2), pp 356-368

8. K. L. McNeill \& J. S. Krajcik, "Supporting Students' Construction of Scientific Explanation through Generic Versus Context-specific Written Scaffolds," The Annual Meeting American Educational Research Association, San Francisco, 2006.

9. J. S. Lederman, N. G. Lederman, S. A. Bartos, L. Selina, S. L. Bartels, A. A. Meyerand R. S. Schwartz, "Meaningful assessment of learners' understandings about scientific inquiry-The views about scientific inquiry (VASI) questionnaire." Journal of Research in Science Teaching vol. 51(1) pp 65-83. 2014.

10. R.G. Duncan, P. Vicky, P. Meliss, E. Dolan, and J. Grady. "The 2003 National Science Teachers Association Standards for Science Teacher Preparation (NSTA-SSTP) were developed to provide guidelines and expectations for science teacher preparation programs. This article is the fourth in a special JSTE series on accreditation written to assist science teacher educators in meeting the NSTA-SSTP. In this article, the authors discuss pedagogical content knowledge...", Journal of Science Teacher Education, vol. 21(1), pp 103-126.

11. AAAS, Project 2061 Benchmarks for Science Literacy: A Tool for Curriculum Reform, 2016, see http://www.project2061.org/publications/bsl/online/i ndex.php?chapter=1\#B3.

12. K. L. McNeill \& J. S. Krajcik, "Helping Students Use Evidence and Reasoning," in Science as Inquiry in the Secondary Setting, edited by J. Luft et al., Arlington : NSTA Press, 2007, pp. 121-146. 
13. K.L. McNeill and J. S. Krajcik, "Framework for Constructing Scientific Explanations," in Framework-supporting Grade 5-8 Students in Constructing Explanations in Science: The Claim, Evidence, and Reasoning Framework for Talk and Writing, New Jersey : Pearson, 2012, pp. 18-42.

14. L.T. Louca, \& Z.C. Zacharia. "Examining learning through modeling in K-6 science education." Journal of Science Education and Technology vol.24(2-3), pp. 192-215, 2015

15. H.K. Wu, \& C.L. Wu. "Exploring the development of fifth graders' practical epistemologies and explanation skills in inquiry-based learning classrooms." Research in Science Education vol. 41(2), pp 319-340, 2011

16. NGSS, DCI Arrangements of the Next Generation Science Standards, Washington, DC: The National Academies Press, 2013

17. J.X. Yao, Y.Y. Guo and K. Neumann, APSE 2, 4, 117 (2016).

18. M. Zghal, H.E. Bouali, Z.B. Lakhdar, and H. Hamam. "The first steps for learning optics: Ibn Sahl's, Al-Haytham's and Young's works on refraction as typical examples." In Education and Training in Optics and Photonics, p. ESB2. Optical Society of America, 2007.

19. C. Andreou, \& A. Raftopoulos, "Lessons from the History of the Concept of the Ray for Teaching Geometrical Optics." Science \& Education vol. 20(10), pp 1007-1037, 2011

20. I. Rustandi, "Perancangan Media Pembelajaran Sains untuk Anak Madya," Thesis: Indonesian Computer University, 2008.

21. A. E. Lawson, IJSME2, 3, 307-338 (2004).

22. K.L.McNeill, D.J. Lizotte, \& J. S. Krajcik, “Supporting Students' Construction of Scientific Explanations Using Scaffolded Curriculum Materials and Assessments," The Annual Meeting (American Educational Research Association, San Francisco, 2004

23. B. Skow, Scientific Explanation. The Oxford Handbook of the Philosophy of Science, UK: Oxford University Press, 2016.

24. C. L. Zembal-Saul, K. L. McNeill, and K. Hershberger, What's Your Evidence Engaging K-5 Children in Constructing Explanations in Science? (Pearson, New Jersey,2013).

25. Harris and J. S. Krajcik, Scientific Explanation Example Rubric Final, Next Generation Science Assessment Project, 2015

26. S. Basu, P. Sengupta and G.Biswas, Res. Sci. Educ.45, 293-324(2014).

27. L. Yuliati, Model-model Pembelajaran Fisika: Teori dan Praktek, Malang: The Institution of Education and Learning Development of the State Universityof Malang, 2008.

28. M. Kipnis, \& A. Hofstein, "The inquiry laboratory as a source for development of metacognitive skills,"
International Journal of Science and Mathematics Education vol. 6, pp 601-627, 2008

29. R. Karplus, \& D.P. Butts. "Science teaching and the development of reasoning." Journal of research in Science Teaching vol.14(2), pp 169-175, 1977

30. W. Harlen, "Helping children's development of inquiry skills." Inquiry in Primary Science Education vol.1(1), pp 5-19, 2014

31. J. C. Moore and L. J. Rubbo, "Scientific reasoning abilities of nonscience majors in physics-based courses." Physical Review Special Topics-Physics Education Research vol. 8(1), 010106, 2012

32. L.Ding, X.Wei \& X.Liu, Res. Sci. Educ. 1-20 (2016).

33. K. Islakhiyah, Sutopo and L.Yuliati, "Pembelajaran Berbasis Fenomena untuk Meningkatkan Kemampuan Penalaran Ilmiah dalam Pembelajaran IPA di SMP," in Inovasi Pembelajaran IPA yang Bermakna dan Mencerdaskan, National Conference Proceedings 1, pp 992-1005. Malang: Graduate School of the State University of Malang, 2016

34. J.W. Creswell \& V.L.P. Clark, Designing and Conducting Mixed Methods Research, California :Sage Thousands Oaks, 2007.

35. P.D. Leedy \& J.E. Ormrod, Practical Research: Planning and Design 8th Edition, New Jersey: Pearson Prentice Hall, 2005.

36. S. Arikunto, Dasar-dasar Evaluasi Pendidikan Edisi 2, Jakarta: Bumi Aksara, 2016.

37. J. R. Landis \& G.G. Koch, "The measurement of observer agreement for categorical data." Biometrics vol 33, pp 159-174, 1977

38. G.A. Morgan, L.L.Nancy, W.G. Gene \& C.B. Karen, SPSS for Introductory Statistics Use and Interpretation (Second Edition), London : Lawrence Erlbaum Associates, Inc. 2004

39. M. Su'aidy \& M. Muchson, Statistika Pendidikan, PowerPoint(Department of Chemistry, State Universityof Malang,Malang, 2016).

40. R.Hake, "Interactive-engagement versus traditional methods: A six-thousand-student survey of mechanics test data for introductory physics courses." American journal of Physics vol. 66(1), pp 64-74, 1998

41. L.Bao, Am. J. Phys.74, 10 (2006).

42. NGSS,Using Phenomena in NGSS-Designed Lessons and Units, 2016, see https://www.nextgenscience.org.

43. F.Ardiyanti and Winarti, Kaunia9, 2, 27-33(2013). 